Advantages of a soft protective layer for good signal-to-noise ratio proton radiographs in high debris environments

N. R. Le Galloudec, J. Cobble, S. L. Nelson, A. Merwin, Y. Paudel, I. Shrestha, G. C. Osborne, K. M. Williamson, V. L. Kantsyrev

January 26, 2011

High Energy Density Physics 
This document was prepared as an account of work sponsored by an agency of the United States government. Neither the United States government nor Lawrence Livermore National Security, LLC, nor any of their employees makes any warranty, expressed or implied, or assumes any legal liability or responsibility for the accuracy, completeness, or usefulness of any information, apparatus, product, or process disclosed, or represents that its use would not infringe privately owned rights. Reference herein to any specific commercial product, process, or service by trade name, trademark, manufacturer, or otherwise does not necessarily constitute or imply its endorsement, recommendation, or favoring by the United States government or Lawrence Livermore National Security, LLC. The views and opinions of authors expressed herein do not necessarily state or reflect those of the United States government or Lawrence Livermore National Security, LLC, and shall not be used for advertising or product endorsement purposes. 


\title{
Advantages of a soft protective layer for good signal-to-noise ratio proton radiographs in high debris environments
}

\author{
Nathalie Renard-Le Galloudec ${ }^{1}$, J. Cobble ${ }^{2}$, S. L. Nelson ${ }^{3}$, A. Merwin ${ }^{1}$, Y. Paudel ${ }^{1}$, I. Shrestha ${ }^{4}$, \\ G. C. Osborne ${ }^{4}$, K. M. Williamson ${ }^{4}$, V. L. Kantsyrev ${ }^{4}$ \\ ${ }^{1}$ Nevada Terawatt Facility, Physics Department, \\ University of Nevada, Reno, Nevada 89557, USA \\ ${ }^{2}$ Los Alamos National Laboratory, Los Alamos, NM 87545 \\ ${ }^{3}$ Lawrence Livermore National Laboratory, Livermore CA 94550 \\ ${ }^{4}$ Physics Department, \\ University of Nevada, Reno, Nevada 89557, USA
}

\begin{abstract}
Proton radiography is a very powerful diagnostic but in some high debris environments it may be challenging to get a good signal-to-noise ratio radiograph to gain insights into the electric and magnetic field topology, and thus the basic physics. Such environments are produced for example on z-pinches and also on lasers such as the National Ignition Facility. We demonstrate here the feasibility of clean, very high signal-to-noise ratio proton radiographs in extremely hostile environments.
\end{abstract}




\section{Introduction}

Proton radiography is a relatively new technique that uses charged particle beams, namely protons, to gain a deeper understanding of the electric and magnetic fields present in plasmas [1-4]. This technique allows a better characterization of the physics associated with High Energy Density plasmas and extremes states of matter of relevance for inertial fusion [5], laboratory astrophysics, shocks, laser plasma interactions, or equation of states. This technique has been applied to laser-driven implosion [6,7] and more recently to holraums [8-10]. Yet it has not been done on z-pinches where it holds the same promises for a better understanding of the physics at play [11]. Z-pinches are one of the most hostile laboratory environments due to the high electromagnetic pulse (EMP), mechanical shock, and destruction zone associated with a copious production of debris [12] during a shot. Such a hostile environment is also found for example on the National Ignition Facility [13], and is expected on the Laser Megajoule [14]. NIF can produce about $180 \mathrm{~kJ}$ of $\mathrm{x}$-rays during a shot and possibly more in specific conditions [15]. Several wire arrays z-pinch facilities have produced x-rays in the range 0.2 to $1.8 \mathrm{MJ}$ [16-20]. Both NIF and the z-pinch facilities generate a large EMP signal [21] as well as high velocity debris. Debris and shrapnel have been measured in the context of damage to and survival of debris shields in facilities such as NIF [13, 22], Omega [23], and Pharos at NRL [13]. The debris also damage the diagnostics thus drastically reducing the signal-to-noise ratio and the ability to extract precise, useable information. We present in this paper a technique that demonstrates the feasibility of proton radiography in such hostile environments by protecting the detectors from debris damage while obtaining a good signal-to-noise ratio for radiography. 


\section{A high debris environment}

At the Nevada Terawatt Facility the Zebra z-pinch (1MA, 2MVolts, 80ns) was used to shoot single planar wire arrays [24-26] to assess the level of debris present and background proton noise that threaten clean proton radiography. The detector of choice was CR39 due to its quasi insensitivity to X-rays, electron and gamma rays [27, 28]. The same detector is also widely used for example on Omega [29, 30]. Figure 1 shows a typical planar or linear wire array (Single Planar Wire Array or SPWA). In this case, the array was built with alumel wires. Figure 2 shows the z-pinch current associated with such a load (solid grey curve, scale to the right) as well as the electron beam current measured (dotted curve, scale to the left) directly above the load at a distance of approximately $90 \mathrm{~mm}$. For this type of load the $\mathrm{x}$-ray emission has been measured to be $20 \mathrm{~kJ}$, which at $9 \mathrm{~cm}$ gives us a fluence of $19 \mathrm{~J} / \mathrm{cm}^{2}$. For a comparison, recent data from NIF [31] give us relevant information. Debris from NIF shots were collected at several points including a distance of $50 \mathrm{~cm}$ from TCC for shot energies from $568 \mathrm{~kJ}$ to $836 \mathrm{~kJ}$. Corresponding fluence with a $90 \%$ conversion efficiency [15] at $50 \mathrm{~cm}$ are: $16 \mathrm{~J} / \mathrm{cm}^{2}$ and $24 \mathrm{~J} / \mathrm{cm}^{2}$. In that later reference [15] the soft x-ray radiation drive is measured with DANTE [32]. DANTE's front filter is about 5 meters from TCC. This gives us a $0.2 \mathrm{~J} / \mathrm{cm}^{2}$ fluence of x-rays. These references and our data point to an optimized distance as a function of load type and geometries. Ref [30] also point out that particle impact craters and molten splat are found 7 meters from Target Chamber Center (TCC), in fewer number than closer to TCC though. Seven meters away from TCC the Xray fluence drops to $0.12 \mathrm{~J} / \mathrm{cm}^{2}$ but the potential for breakage remains.

A future publication including a more in depth study of debris collection similar to NIF in our Zebra z-pinch is in progress [19]. 
In our measurements, the Faraday cup filtered with a $10 \mu \mathrm{m} \mathrm{Cu}$ filter (electron cutoff of $63-\mathrm{keV}$ ) measured a maximum electron current of $3.4 \mathrm{kA}$. Along with the electron beam, vaporized material, ions, and macroscopic pieces of material land on the filter in front of the Faraday cup. This is the location we choose to assess the level of debris in a worst-case scenario, but also a reasonable choice for on-axis proton radiography [11]. Prior to a shot, a single piece of clear CR39 was taped in the front of the Faraday cup and the $\mathrm{Cu}$ filter. At first, our attempts resulted in shattered CR39, and quickly progressed to quasi-intact (unbroken) CR39 covered with debris (Fig. 3a) by putting the CR39 on a flat support and not a ring shaped one like the edge of the Faraday cup. Figure $3 \mathrm{~b}$ shows that same piece of CR39 after etching it for 60 minutes in $6.0-\mathrm{N} \mathrm{NaOH}$ solution at $70 \pm 1^{\circ} \mathrm{C}$. Details on the etching process and the response of CR39 can be found in [27]. The etched CR39 clearly shows remaining debris covering the detector. Figure $3 \mathrm{c}$ is a microscopic picture of this etched CR39. It shows dark areas where remaining material still covers the detector, a background of proton/ion tracks and areas that have been broken or impacted as if by bullets of flying material. These are similar to the impact of a small stone in your windshield, and like those, sometimes cracks can be seen spreading from the impact location. It is clear from these typical results that a clear, high signal-to-noise ratio result is a challenging task, especially with the goal of obtaining clear 2D radiographs similar to those in laser plasmas interaction [1-4]. Note that of course we choose an on-axis location and that a radial location is possibly less challenging. 


\section{Obtaining a clean high signal-to-noise ratio}

A different approach successfully eliminated debris, cracks and breakage of the detector. We covered another piece of CR39 with a thin layer of transparent glycerol soap and taped it to the front of the Faraday cup. We used a similar SPWA load with the same drive current from the z-pinch as showed in Figure 2. Figure 4a shows the CR39 immediately after the shot with the layer of soap covered in debris. Figure $4 \mathrm{~b}$ shows the same CR39 after a simple rinse with water. We then processed this CR39 in precisely the same way as the one before. Figure 4c shows tracks left by the protons in the CR39 after etching. The CR39 is transparent, unbroken and holds data with excellent contrast - a high signal-to-noise situation. In our case the protective layer used is soft enough to absorb and diffuse the momentum and thus allows the CR39 to not crack or break. This technique is reproducible and the results showed here are typical results. It clearly demonstrates the feasibility of clear, high signal-to-noise proton radiography in very hostile environments such as z-pinches, and high-power lasers such as NIF and Laser Megajoule. Another well-known technique from the laser target interaction community consists of placing a solid filter in front of the detector layers. This solid detector is very often a 12 micron thick Aluminum foil in standard laser target proton radiography. Being solid, it does not absorb and diffuse the momentum of the debris landing on the detector pack. In our case, where bullet-like debris land on the detector, a solid filter transmits the momentum and this results in breakage of the CR39 detector. Al witness plates were fielded on NIF [30] 25 to 50cm from Target Chamber Center. Each plate was of a thickness included between $1.18 \mathrm{~mm}$ and $1.22 \mathrm{~mm}$. Evidence of Aluminum surface melt were observed, as well as debris splats and particle impact craters. A soft material such as a glycerol layer will stop the debris and diffuse their momentum resulting in an 
unbroken and thus useable detector. In other words, you need to protect the detector so that the debris do not embed themselves into it reducing the signal to noise ratio but also so that it does not break (in the case of CR39) or melts (if RCF layers are used). Our soft glycerol layer addresses both aspects. A thin layer of gel-like material that one can cut to the appropriate size may also work very well and would be easier to handle.

To assess the out-gassing rate, we used a $2-\mathrm{cm}$ by $3-\mathrm{cm}$ block of glycerol soap with a thickness of $1.5 \mathrm{~cm}$. This large sample did not impact our ability to evacuate the chamber to shot pressure (10-5 $\mathrm{T})$ in the nominal amount of time used for all shots $(20 \mathrm{~min})$. In practical applications, as for the experimental data reported earlier in this article, the sample is 50 - 100 $\mu \mathrm{m}$ thick -- much thinner than the piece used for the out-gassing test. Current technologies are able to precisely control the process of thin layer deposition, such as vapor deposition for example. Therefore, we believe that problems with out-gassing should be minimal. We also performed stopping power calculation in glycerol. The target density (C3H8O3) was 1.261 g/cc. Figure 5 shows the range for different energy protons. We see that a $50-\mu \mathrm{m}$ layer would stop protons with a slightly lower energy than $2 \mathrm{MeV}$. In many experiments, proton energies greatly exceed $2 \mathrm{MeV}$. For example in ion-acceleration experiments [33] and with fusion (D-He3) protons [8] for radiography, energies go up to $\sim 20 \mathrm{MeV}$. Thus, even if the layer stops up to $2 \mathrm{MeV}$ protons, we are still able to use/diagnose the high-energy protons without loss or with minimal loss of data to obtain a high signal-to-noise ratio proton radiograph.

This technique may also be useful to apply to the measurement of neutron flux with CR39 [34] in hostile or high debris environments. Finally Figure 6 shows a $\mathrm{C}^{4+}$ ion track with energies approaching $15 \mathrm{MeV}$ obtained at the University of Rochester EP laser [36] with a Thomson parabola (TPIE). The individual $\mathrm{C}$ pits in the track extend from the upper left to the 
lower right, and superimposed on the track - over the entire figure - is a uniform background of noise. It is believed that the uniform background comes from protons with an average energy less than $1 \mathrm{MeV}$ that do not go through the TPIE pinhole but scatter into the detector region through a bounce off of the top of the cart that holds the TPIE. The solid angle for this is a million times higher than the collection solid angle of the pinhole. The data showed in figure 6 is representative of several species of ions. All of them were affected by this problem. In such cases, a thin layer of soluble material would dramatically enhance the signal-to-noise ratio and thus the quality of the Thomson parabola data. Although the energy cutoff for $\mathrm{C}$ ions, for which the soap has higher stopping power, is higher than for protons, the statement is definitely true for protons.

The layer of clear glycerol soap also strongly attenuates x-rays. The SPWA total radiation output is about $20 \mathrm{~kJ}$ in extreme ultraviolet (EUV) and soft X-ray spectral region $(<1-2 \mathrm{keV})$. This radiation is totally absorbed by $50 \mu \mathrm{m}$ thick soap. Harder radiation (which can penetrate soap layer) is just of $1-2 \%$ of the total output. So, after the glycerol soap layer, the harder radiation energy density on the CR39 surface is much lower than $100 \mathrm{~mJ} / \mathrm{cm}^{2}$, which is small compare to the CR39 sensitivity [33]. This may enable Radiochromic film (RCF, a detector usually sensitive to x-rays) to be used as a way to refine the time resolution of the proton radiography of z-pinches. Planar wire arrays as well as cylindrical wire arrays were extensively studied on several facilities [37,38] with a total power in the x-ray ranging from $0.2 \mathrm{TW}$ (similar to our SPWA shots) to $0.6 \mathrm{TW}$. Double planar wire arrays and cylindrical compact wire arrays were also compared [39]. Double planar wire arrays were found to be the best radiators for a 1MA scale z-pinch, we thus expect the method described here to be valid for multi-wire cylindrical arrays for this scale z-pinch. 
Taking the idea further, a water-soluble coating allows debris and shrapnel to be manipulated separately from the coating itself. This means that the sprayed materials may be removed by washing without destroying the detector, and can also be studied separately. Aerogels have been used by NASA [40] and then on NIF [21] to study debris, but the debris stay embedded in the porous silica material that composes the aerogel. Therefore this could especially be of interest on facilities such as NIF where we will be able to access a new range of parameters in the laboratory and where new materials will be created. Such thin soluble layers are used on the wafers in laser processing of wafers and successfully eliminate debris issues [41].

\section{Conclusion}

By using a soft, water soluble material to protect CR39 from the debris produced in a typical 1-MA z-pinch we demonstrated the feasibility of proton radiography in such hostile environments. This technique can also be applied to high power lasers such as NIF or the Megajoule where debris are a concern but where the potential to obtain new, exciting data is extremely high. Other aspects would be the ability to free the debris from the capture material to study them.

This work was supported by the National Nuclear Security Administration under cooperative agreements DE-FC52-03NA00156 at the University of Nevada Reno, performed in part under the auspices of the U.S. Department of Energy by Lawrence Livermore National Laboratory under Contract DE-AC52-07NA27344, and funded in part by the Laboratory Directed Research and Development Program at LLNL under project tracking code 09-ERD085. LLNL-JRNL-467712 
Figure 1 Typical single planar wire array load

Figure 2 Typical z-pinch current (solid grey line) and Faraday cup signal (dotted line) for the array of figure 1 (Shot \# 1954, wire material is alumel, wires number $N=12$, wire diameter $\Phi=10.16 \mu \mathrm{m}$, inter-wire gap is $0.7 \mathrm{~mm}$ ).

Figure 3 Figure 3a shows the black coating due to debris produced during the shot on an otherwise clear piece of CR39. Figure 3b is the same CR39 after 60 minutes of etching. Figure 3c shows the remaining debris, damage, and proton tracks on the CR39.

Figure 4 Figure 4a shows the black coating due to debris produced during the shot on an otherwise clear piece of CR39 covered with a thin layer of soap. Figure $4 \mathrm{~b}$ is the same CR39 after the soap layer has been removed. Figure $4 \mathrm{c}$ shows clear proton tracks on the CR39 and no residual debris or damage.

Figure 5 Proton stopping distance as a function of energy in glycerol

Figure 6 Carbon 4+ ion tracks in CR39 in the Thomson Parabola (TPIE) from an OmegaEP shot 


\section{References:}

[1] L. Romagnani, J. Fuchs, M. Borghesi, P. Antici, P. Audebert, F. Ceccherini, T. Cowan, T. Grismayer, S. Kar, A. Macchi, P. Mora, G. Pretzler, A. Schiavi, T. Toncian, and O. Willi, PRL 95, 195001 (2005).

[2] M. Borghesi, P. Audebert, S.V. Bulanov, T. Cowan, J. Fuchs, J.C. Gauthier, A.J. Mackinnon, P.K. Patel, G. Pretzler, L. Romagnani, A. Schiavi, T. Toncian and O. Willi Laser and Particle Beams, Volume 23, Issue 03, pp. 291-295 (Sept 2005).

[3] M. Borghesi, D.H. Campbell, A. Schiavi, O. Willi, A.J. Mackinnon, D. Hicks, P. Patel, L.A. Gizzi, M. Galimberti and R.J. Clarke, Laser and Particle Beams, Volume 20 , Issue 04, pp. 641641, (Oct 2002).

[4] S. Kar, M. Borghesi, P. Audebert, A. Benuzzi-Mounaix, T. Boehly, D. Hicks, M. Koenig, K. Lancaster, S. Lepape, A. Mackinnon, P. Norreys, P. Patel, L. Romagnani, High Energy Density Physics 4, Issue 1-2, p. 26-40 (2008).

[5] R. Paul Drake, High Energy Density Physics (Springer New York, 2006)

[6] A. J. Mackinnon, P. K. Patel, M. Borghesi, R. C. Clarke, R. R. Freeman, H. Habara, S. P. Hatchett, D. Hey, D. G. Hicks, S. Kar, M. H. Key, J. A. King, K. Lancaster, D. Neely, A. Nikkroo, P. A. Norreys, M. M. Notley, T.W. Phillips, L. Romagnani, R. A. Snavely, R. B. 
Stephens, and R. P. J. Town, PRL 97, 045001 (2006)

[7] J. R. Rygg, F. H. Séguin, C. K. Li, J. A. Frenje, M. J.-E. Manuel, R. D. Petrasso, R. Betti, J. A. Delettrez, O. V. Gotchev, J. P. Knauer, D. D. Meyerhofer, F. J. Marshall, C. Stoeckl, W. Theobald' Science, Vol. 319, No 5867, pp. 1223-1225, 29 February 2008

[8] C. K. Li, F. H. Séguin, J. R. Rygg, J. A. Frenje, M. Manuel, R. D. Petrasso $\square$ R. Betti, J. Delettrez, J. P. Knauer, F. Marshall, D. D. Meyerhofer, D. Shvarts, V. A. Smalyuk, and C. Stoeckl $\square$ O. L. Landen, R. P. J. Town, C. A. Back and J. D. Kilkenny, Phys Rev. Lett. 100, $225001(2008)$

[9] C. K. Li, F. H. Séguin, J. A. Frenje, P. A. Amendt, R. P. J. Town, O. L. Landen, J. R. Rygg $\square$ R. Betti, J. P. Knauer, D. D. Meyerhofer, J. M. Soures, C. A. Back, J. D. Kilkenny, and A. Nikroo Phys. Rev. Lett. 102, 205001 (2009)

[10] G. Sarri, M. Borghesi, C. A. Cecchetti, L. Romagnani, R. Jung, O. Willi, D. J. Hoarty, R. M. Stevenson, C.R.D. Brown, S. F. James, P. Hobbs, J. Lockyear, S. V. Bulanov, and F. Perogaro, Eur. Phys. J. D, 55, Number 2, p. 299-303 (Nov 2009)

[11] F. Beg, S. Bott, M. Wei, proposal to DOE/NSF grant, 2008 - awarded [12] Fielding of the on-axis diagnostic package at Z, M. J. Hurst et al., Report SAND—981202C CONF - 980605, 1998, also in Rev. Sci. Instrum. 70, 468 (1999) 
[13] M. C. Miller, Debris characterization diagnostic for the NIF, RSI 72, 537, 2001

[14] J. L. Bourgade et al., Diagnostic components in harsh radiation environments: Possible overlap in R\&D requirements of inertial confinement and magnetic fusion system, RSI 79, 10F301 (2008)

[15] Kline et al., PRL 106, 085003 (2011)

[16] V. Ivanov et al., Phys. Rev. E 79, 056404 (2009)

[17] C. Deeney et al., Phys. Rev. E 56, 5945 (1997); C Deeney et al., Phys. Rev. Lett. 81, 4883 (1998)

[18] S. Lebedev et al., Plasma Phys. Control. Fusion 47 A91 (2005)

[19] B. Jones et al., Phys. Rev. Lett. 95, 225001 (2005)

[20] S. Nelson et al., publication in progress

[21] C. J. Brown Jr. et al., proceedings of IFSA 2007, Kobe, Japan

[22] D. C. Eder, A E Koniges, O L Landen, N D Masters, A C Fisher, O S Jones, T I Suratwala, and L J Suter, Debris and Shrapnel Mitigation Procedure for NIF Experiments, Journal of Physics: Conference Series 112 (2008) 032023 
[23] Mike Tobin, Jim Andrew, David Eder, David Haupt, Andrew Johannes, and Bill Brown, Characterizing Shrapnel and Debris Produced in High Power Laser Experiments, $3^{\text {rd }}$ International Conference on Inertial Fusion Sciences and Applications, Monterey, California, September 7-12, 2003

[24] Kantsyrev V., Rudakov L., Safronova A, et al., High Energy Density Physics 3, Issue 1-2, p.136 (2007).

[25] I. Shrestha, V. Kantsurev, A Safronova et al., High Energy Density Physics, 6, Issue 1, p.113-120 (2010).

[26] F. Yilmaz et al., Journal of Quantitative Spectroscopy \& Radiative Transfer 109 (2008) $2877-2890$

[27]R. L. Fleisher, P. B. Price, and R. M. Walker, J. Appl. Phys. 36, 3645, 1965

[28] S. Gaillard, J. Fuchs, N. Renard-Le Galloudec and T. E. Cowan, RSI 78, 013304, 2007

[29] J. A. Frenje, C. K. Li, F. H. Seguin, D. G. Hicks, S. Kurebayashi, R. D. Petrasso, S. Roberts, V. Yu. Glebov, D. D. Meyerhofer, T. C. Sangster, J. M. Soures, C. Stoeckl, C. Chiritescu, G. J. Schmid and R. A. Lerche, RSI, 73, 2597, 2002.

[30] F. H. Seguin, J. A. Frenje, C. K. Li, D. G. Hicks, S. Kurebayashi, J. R. Rygg, B.-E. Schwartz, and R. D. Petrasso, S. Roberts, J. M. Soures, D. D. Meyerhofer, T. C. Sangster, 
J. P. Knauer, C. Sorce, V. Yu. Glebov, and C. Stoeckl, T. W. Phillips, R. J. Leeper, K. Fletcher and S. Padalino, RSI. 74, 975, 2003.

[31] J.M. Gostic, " Development of Radiochemical Diagnostics at NIF Through Collection of Solid and Gaseous Debris" Presentation at the JINA Workshop-Nuclear Physics in Hot Dense plasma, London UK, March 13-14, 2011

[32] E. L Dewald et al., RSI, 75, 3759 (2004)

[33] K. A. Flippo, E. d'Humières, S. A. Gaillard, J. Rassuchine, D. C. Gautier, M. Schollmeier, F. Nurnberg, J. L. Kline, J. Adams, B. Albright, M. Bakeman, K. Harres, R. P. Johnson, G. Korgan, S. Letzring, S. Malekos, N. Renard-LeGalloudec, Y. Sentoku, T. Shimada, M. Roth, T. E. Cowan, J. C. Fernández, and B. M. Hegelich, Phys Plasma 15, 056709, 2008.

[34] I. Lengar et al., Nucl. Instr. And Meth. in Phys. Research Section B, Vol. 192 (4) p. 440444, 2001.

[35] J.H. Kelly, L.J. Waxer, V. Bagnoud, I.A. Begishev, J. Bromage, B.E. Kruschwitz, T.J. Kessler, S.J. Loucks, D.N. Maywar, R.L. McCrory, D.D. Meyerhofer, S.F.B. Morse, J.B. Oliver, A.L. Rigatti, A.W. Schmid, C. Stoeckl, S. Dalton, L. Folnsbee, M.J. Guardalben, R. Jungquist, J. Puth, M.J. Shoup III, D. Weiner and J.D. Zuegel, J. Phys. IV France, Vol. 133, p. 75-80, June 2006 
[36] K. Amemiya et al., "Soft x-ray imaging using CR-39 plastics with AFM readout. Nuclear Instr. And Methods in Physics Research Section B: Beam Interactions with Materials and atoms. V. 187, iss.3, March 2002, pp. 361-366.

[37] M. Masarakis et al. Phys Rev E. 79, 016412 (2009)

[38] B. Jones et al., Sandia report, SAND2007-6337, Oct 2007

[39] V. Kantsyrev et al., HED, 5, (2009) 115-123

[40] F. Hörz et al., Icarus Volume 147, Issue 2, Oct. 2000, P. 559-579.

[41] K. C. Su, H. H. Lu, S. H. Chen, C. D. Tsai, Y.C. Chou, W.J Wu, G.Q. Wu, and J.C. Moore, “A novel Water washable coating for avoiding contamination during dry laser dicing operations", CS MANTECH Conference, May 14-17, Austin Tx (2007). 